\title{
New version of case mix tool for special care and paediatric dentistry launched
}

The BDA has announced the launch of the new version of the BDA case mix tool, promising to build on an unrivalled approach to scoring patient complexities, with new criteria covering paediatric dentistry.

The announcement, made at the Royal College of Surgeons, follows calls from commissioners to use the tool to measure paediatric dental patient complexities the tool has received a root and branch update, with new criteria geared around the needs of young patients, following input from the British Society of Disability and Oral Health and British Society of Paediatric Dentistry. Definitions already included for adult patients have also been revised.

Discussions with IT suppliers are already ongoing and the BDA will be producing training on the new tool later in 2019.

Although CDS dentists are its prime users, the tool can be used by general dental practitioners or secondary care providers who are treating patients requiring special care and paediatric dentistry. The BDA is now working across wider health and social care sectors to promote the model.

Chair of the BDA's England Community Dental Services Committee, Charlotte Waite, said: 'Since its inception BDA case mix has demonstrated to commissioners the challenges and value of the work community and special care dentists do. This new version will take this approach to the next level.

'For over a decade BDA case mix has been used by individual dentists to demonstrate the complexity of their caseload and clinical directors to benchmark the clinics within their areas. This new version builds on a tried and tested system which has supported colleagues operating in all four countries of the UK.

'The NHS Long Term Plan pledges links to learning disability and autism services, and a holistic approach to care.
It's an approach we take on a daily basis, empowered by BDA case mix, and now children can benefit fully with a system designed around their unique needs.

'The sheer complexity and skill of the services we deliver can often be lost on health officials and commissioners. And that's where BDA case mix comes into its own. We have a framework that can help colleagues across the profession break down barriers, reduce health inequalities and deliver high quality dental care for all our patients.'

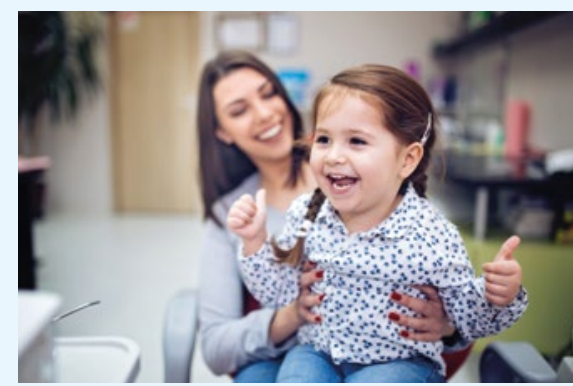

\section{Dentists treating the most vulnerable break impasse at Stormont}

The vital role performed by the community dental service must never again be taken for granted, says the British Dental Association following official confirmation their terms and conditions will finally be brought into the $21^{\text {st }}$ century. Northern Ireland's Community Dental Service were the last healthcare workers in the whole of the UK to be working to contracts drafted in the 1980s.

The service provides dental care for people of all ages across Northern Ireland including children and adults with learning disabilities, patients with health problems, phobias, and those unable to leave their homes.

Despite a deal being reached, and funding allocated to local Trusts by the Department of Health in 2016, Stormont officials had refused to proceed to implement the contract without formal ministerial approval. Following BDA pressure, permanent secretaries have finally agreed to rollout of the 'new' contract from April 2019.
Last year's Health and Social Care Workforce Strategy 2026 identified growing recruitment problems, and that a significant number of the most experienced community dentists are approaching retirement, with up to $40 \%$ reported to be potentially retiring by 2025 .

The new deal will see pay finally come into line with community colleagues in the rest of the UK, and will be backdated to 1 April 2015.

Here has been

an advertisement.

SPRINGERNATURE 